\title{
CLINICAL \\ CHEMISTRY AND \\ LABORATORY \\ MEDICINE
}

Published in Association with the European Federation of Clinical Chemistry and

Laboratory Medicine (EFLM)
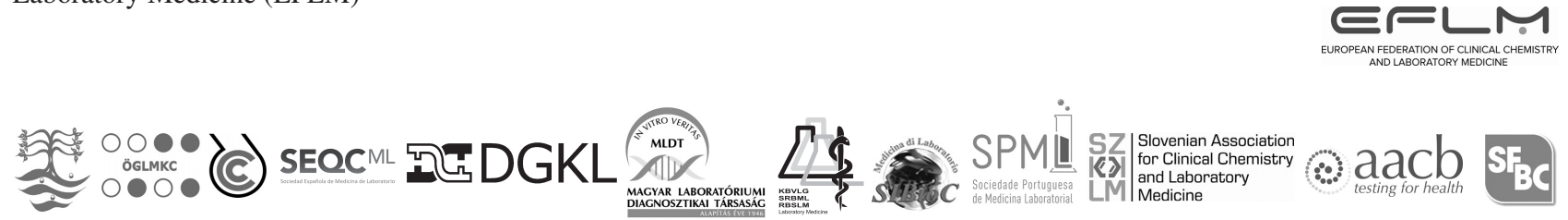

eaacb

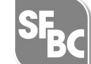

CCLM is the official journal of the Association of Clinical Biochemists in Ireland (ACBI), the Austrian Society of Laboratory Medicine and Clinical Chemistry (ÖGLMKC), the German Society for Clinical Chemistry and Laboratory Medicine (DGKL), the Hungarian Society of Laboratory Medicine (MLDT), the Royal Belgian Society of Laboratory Medicine (RBSLM), the Italian Society of Clinical Biochemistry and Clinical Molecular Biology (SIBioC), the Portuguese Society of Clinical Chemistry, Genetics and Laboratory Medicine (SPML), the Slovenian Association for Clinical Chemistry and Laboratory Medicine (SZKKLM) and the Spanish Society of Laboratory Medicine (SEQC). CCLM is affiliated with the Australasian Association of Clinical Biochemists (AACB) and Société Francaise de Biologie Clinique (SFBC).

\section{EDITOR-IN-CHIEF \\ Mario Plebani \\ Padova, Italy}

\section{ASSOCIATE EDITORS}

Giuseppe Lippi

Reviews Editor

Verona, Italy

Philippe Gillery

Reims, France

Ronda Greaves

Bundoora, Australia

Karl J. Lackner

Mainz, Germany

Bohuslav Melichar

Olomouc, Czech Republic

Deborah A. Payne

Denver, CO, USA

Peter Schlattmann

Jena, Germany

\section{EDITORIAL BOARD}

Ivan Brandslund

Odense, Denmark
Janne Cadamuro

Salzburg, Austria

Etienne Cavalier

Liege, Belgium

Sail Chun

Seoul, Korea

Pradeep Kumar Dabla

New Delhi, India

Vincent De Guire

Montreal, Canada

Vincent Delatour

Paris, France

Eleftherios P. Diamandis

Toronto, Canada

Rajiv T. Erasmus

Stellenbosch, South Africa

Emmanuel Favaloro

Westmead, Australia

Julien Favresse,

Brussels, Belgium

Juan M. Guerrero

Seville, Spain

João Tiago Guimarães

Porto, Portugal

Liam Heaney

Loughborough, UK
Brandon M. Henry,

Cincinnati, OH, USA

Markus Herrmann

Graz, Italy

Martin Hersberger

Zurich, Switzerland

Johannes J.M.L. Hoffmann

Nuenen, Netherlands

Zhi-De Hu

Hohhot, P.R. China

Berend Isermann

Magdeburg, Germany

Joannes F.M. Jacobs,

Nijmegen, Netherlands

Petr Jarolim

Boston, MA, USA

Graham Jones

Darlinghurst, NSW, Australia

János Kappelmayer

Debrecen, Hungary

Peter Kavsak

Toronto, Canada

Christos Kroupis

Athens, Greece

Leslie Charles Lai

Kuala Lumpur, Malaysia

Michael Laposata

Galveston, TX, USA
Tze Ping Lo

Singapore

David Meyre

Hamilton, Canada

Yesim Ozarda

Bursa, Turkey

Tomris Özben

Antalya, Turkey

Vladimir Palicka

Hradec Králové,

Czech Republic

Mauro Panteghini

Milan, Italy

Geraldo Picheth

Curitiba, Brazil

Ted E. Schutzbank,

San Diego, CA, USA

Ana-Maria Simundic

Zagreb, Croatia

Grazyna Sypniewska

Bydgoszcz, Poland

Michael Vogeser

Munich, Germany

Maria Alice V. Willrich

Rochester, MN, USA

MANAGING EDITOR

Heike Jahnke

Berlin, Germany

\section{DE GRUYTER}


ABSTRACTED/INDEXED IN Analytical Abstracts; Baidu Scholar; Biobase; Cabells Journalytics; CABI (over 50 subsections); Case; Chemical Abstracts Service (CAS) - CAplus; Chemical Abstracts Service (CAS) - SciFinder; CNKI Scholar (China National Knowledge Infrastructure); CNPIEC - cnpLINKer; Dimensions; EBSCO (relevant databases); EBSCO Discovery Service; EMBASE; Genamics JournalSeek; Google Scholar; ICAP Alcohol Information Databases; Japan Science and Technology Agency (JST); J-Gate; Journal Citation Reports/Science Edition; JournalGuide; JournalTOCs; KESLI-NDSL (Korean National Discovery for Science Leaders); Medline; Meta; Microsoft Academic; MyScienceWork; Naver Academic; Naviga (Softweco); Norwegian Register for Scientific Journals, Series and Publishers; Pathway Studio; Primo Central (ExLibris); ProQuest (relevant databases); Publons; PubMed; PubsHub; QOAM (Quality Open Access Market); ReadCube; Reaxys; SCImago (SJR); SCOPUS; Semantic Scholar; Sherpa/RoMEO; Summon (ProQuest); TDNet; TEMA Technik und Management; Text Mining; Ulrich's Periodicals Directory/ ulrichsweb; WanFang Data; Web of Science - Biological Abstracts; Web of Science - BIOSIS Previews; Web of Science - Current Contents/Life Sciences; Web of Science - Prous Science Integrity; Web of Science - Science Citation Index; Web of Science - Science Citation Index Expanded; WorldCat (OCLC); Yewno Discover.

CCLM is the official journal of the Association of Clinical Biochemists in Ireland (ACBI), the Austrian Society of Laboratory Medicine and Clinical Chemistry (ÖGLMKC), the German Society for Clinical Chemistry and Laboratory Medicine (DGKL), the Hungarian Society of Laboratory Medicine (MLDT), the Royal Belgian Society of Laboratory Medicine (RBSLM), the Italian Society of Clinical Biochemistry and Clinical Molecular Biology (SIBioC), the Portuguese Society of Clinical Chemistry, Genetics and Laboratory Medicine (SPML), the Slovenian Association for Clinical Chemistry and Laboratory Medicine (SZKKLM) and the Spanish Society of Laboratory Medicine (SEQC). CCLM is affiliated with the Australasian Association of Clinical Biochemists (AACB) and Société Francaise de Biologie Clinique (SFBC).

The publisher, together with the authors and editors, has taken great pains to ensure that all information presented in this work (programs, applications, amounts, dosages, etc.) reflects the standard of knowledge at the time of publication. Despite careful manuscript preparation and proof correction, errors can nevertheless occur. Authors, editors and publisher disclaim all responsibility for any errors or omissions or liability for the results obtained from use of the information, or parts thereof, contained in this work.

The citation of registered names, trade names, trademarks, etc. in this work does not imply, even in the absence of a specific statement, that such names are exempt from laws and regulations protecting trademarks etc. and therefore free for general use.

\section{ISSN 1434-6621 · e-ISSN1437-4331 · CODEN CCLMFW}

All information regarding notes for contributors, subscriptions, Open access, back volumes and orders is available online at www.degruyter.com/cclm.

RESPONSIBLE EDITOR(S) Prof. Dr. Mario Plebani, Università di Padova, Dipartimento di Medicina di Laboratorio, Azienda Ospedaliera di Padova, Via Nicolo Giustiniani 2, 35131 Padova, Italy. Tel.: +390 (0)49 821 2792, Fax: +390 (0)49 663 240, e-mail: mario.plebani@unipd.it

PUBLISHER Walter de Gruyter GmbH, Berlin/Boston, Genthiner Str. 13, 10785 Berlin, Germany

JOURNAL COORDINATOR Heike Jahnke, De Gruyter, Genthiner Str. 13, 10785 Berlin, Germany, Tel.: +49 (0)30 26005 - 220 ,

Fax: +49 (0)3026005-325, e-mail: heike.jahnke@ degruyter.com

RESPONSIBLE FOR ADVERTISEMENTS Markus Kügel, De Gruyter, Rosenheimer Str. 143, 81671 Munich, Germany. Tel.: +49 (0) 89 76 902-424, e-mail: anzeigen@ degruyter.com

(C) 2022 Walter de Gruyter GmbH, Berlin/Boston, Germany

TYPESETTING TNQ Technologies, Chennai, India

PRINTING Franz X. Stückle Druck und Verlag e.K., Ettenheim

COVER ILLUSTRATION Research lab @ Eisenhans. Permission to use the image on the cover granted by Fotolia LLC.

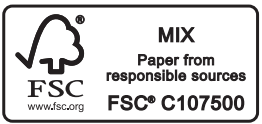




\section{Contents}

\section{Editorial}

Simona Ferraro and Elia Mario Biganzoli

The clinical value of assessing the inter-method bias: the lesson from prostate specific antigen

measurement 149

\section{Mini Review}

Sheila X. Soh, Tze Ping Loh, Sunil K. Sethi and Lizhen Ong Methods to reduce lipemic interference in clinical chemistry tests: a systematic review and recommendations -152

\section{Opinion Paper}

Bernhard Strasser, Josef Tomasits, Alexander Fellner and Thomas Lambert

Troponin interference with special regard to macrocomplex formation -162

\section{Guidelines and Recommendations from Scientific Societies}

Aldo Clerico, Martina Zaninotto, Alberto Aimo, Ruggero Dittadi, Domenico Cosseddu, Marco Perrone, Andrea Padoan, Silvia Masotti, Lucia Belloni, Marco Migliardi, Antonio Fortunato, Tommaso Trenti, Lucia Malloggi, Piero Cappelletti, Gianni Antonio Galli, Sergio Bernardini, Laura Sciacovelli and Mario Plebani Use of high-sensitivity cardiac troponins in the emergency department for the early rule-in and rule-out of acute myocardial infarction without persistent ST-segment elevation (NSTEMI) in Italy 169

\section{Genetics and Molecular Diagnostics}

Chad Fibke, Sylvie Giroux, André Caron, Elizabeth Starks, Jeremy D.K. Parker, Lucas Swanson, Loubna Jouan, Sylvie Langlois, Guy Rouleau, François Rousseau and Aly Karsan

Effect of preexamination conditions in a centralizedtesting model of non-invasive prenatal screening - 183

\section{General Clinical Chemistry and Laboratory Medicine}

Manuela Lotierzo, Florin Olaru-Soare, Anne-Marie Dupuy, Maëlle Plawecki, Françoise Paris and Jean-Paul Cristol Comparative study of human growth hormone measurements: impact on clinical interpretation -191

Lauren M. Forgrave, J. Grace van der Gugten, Quyen Nguyen and Mari L. DeMarco

Establishing pre-analytical requirements and maximizing peptide recovery in the analytical phase for mass spectrometric quantification of amyloid- $\beta$ peptides 1-42 and 1-40 in CSF -198

Johan Gobom, Lucilla Parnetti, Pedro Rosa-Neto, Martin Vyhnalek, Serge Gauthier, Samuela Cataldi, Ondrej Lerch, Jan Laczo, Katerina Cechova, Marcus Clarin, Andrea L. Benet, Tharick A. Pascoal, Neserine Rahmouni, Manu Vandijck, Else Huyck, Nathalie Le Bastard, Jenna Stevenson, Mira Chamoun, Daniel Alcolea, Alberto Lleó, Ulf Andreasson, Marcel M. Verbeek, Giovanni Bellomo, Roberta Rinaldi, Nicholas J. Ashton, Henrik Zetterberg, Katerina Sheardova, Jakub Hort and Kaj Blennow

Validation of the LUMIPULSE automated immunoassay for the measurement of core AD biomarkers in cerebrospinal fluid -207

Katharina Habler, Bernhard Koeppl, Franz Bracher and Michael Vogeser Targeted profiling of 24 sulfated and non-sulfated bile acids in urine using two-dimensional isotope dilution UHPLC-MS/MS - 220

Julien Favresse and Joris Delanghe High-resolution capillary electrophoresis for the determination of carbamylated albumin -229 
Jasmijn A. van Balveren, Wilhelmine P.H.G. Verboeket-van de Venne, Carine J.M. Doggen, Lale Erdem-Eraslan, Albert J. de Graaf, Johannes G. Krabbe, Ruben E.A. Musson, Wytze P. Oosterhuis, Yolanda B. de Rijke, Heleen van der Sijs, Andrei N. Tintu, Rolf J. Verheul, Rein M.J. Hoedemakers and Ron Kusters, on behalf of the Dutch Society for Clinical Chemistry and Laboratory Medicine, task group 'SMILE': Signaling Medication Interactions and Laboratory test Expert system Real-time monitoring of drug laboratory test interactions: a proof of concept -235

Niina Pitkänen, Armin Finkenstedt, Claudia Lamina, Markus Juonala, Mika Kähönen, Kari-Matti Mäkelä, Benjamin Dieplinger, Andre Viveiros, Andreas Melmer, Isabella Leitner, Ludmilla Kedenko, Ilkka Seppälä, Jorma S.A. Viikari, Thomas Mueller, Florian Kronenberg, Bernhard Paulweber, Terho Lehtimäki, Heinz Zoller, Olli T. Raitakari and Hans Dieplinger

Afamin predicts the prevalence and incidence of nonalcoholic fatty liver disease -243

\section{Reference Values and Biological Variations}

Simon Lykkeboe, Stine Linding Andersen,

Claus Gyrup Nielsen, Peter Vestergaard

and Peter Astrup Christensen

Blood sampling frequency as a proxy for comorbidity indices when identifying patient samples for review of reference intervals -252

Sofie Taageby Nielsen, Nina Strandkjær, Ida Juul Rasmussen, Malene Kongsgaard Hansen, Rikke Mohr Lytsen, Pia R. Kamstrup, Line Rode, Jens P. Goetze, Kasper Iversen, Henning Bundgaard and Ruth Frikke-Schmidt

Coagulation parameters in the newborn and infant - the Copenhagen Baby Heart and COMPARE studies — 261

\section{Hematology and Coagulation}

Vanja Radišić Biljak, Ivana Lapić, Valentina Vidranski, Ivona Herceg, Franciska Tomić, Brankica Šimac, Martina Horvat, Helena Čičak, Dora Vuljanić, Adrijana Dorotić and Ana Nikler Policies and practices in the field of laboratory hematology in Croatia - a current overview and call for improvement -271

\section{Cardiovascular Diseases}

Carel J. Pretorius, William Parsonage, Louise W. Cullen, Urs Wilgen, Elzahn De Waal, Sandra Klingberg, Goce Dimeski, Rob White, Jaimi Greenslade and Jacobus P.J. Ungerer

Evaluation of the Atellica TnIH cardiac troponin I assay and assessment of biological equivalence - 283

\section{Infectious Diseases}

Christoph Buchta, Jeremy V. Camp, Jovana Jovanovic, Ulla Radler, Bernhard Benka, Elisabeth

Puchhammer-Stöckl, Mathias M. Müller, Andrea Griesmacher, Stephan W. Aberle and Irene Görzer Inadequate design of mutation detection panels prevents interpretation of variants of concern: results of an external quality assessment for SARS-CoV-2 variant detection -291

\section{Online Only Content}

https://www.degruyter.com/view/j/cclm.2022.60.issue2/issue-files/cclm.2022.60.issue-2.xml

\section{Letters to the Editors}

Gian Luca Salvagno, Brandon M. Henry, Laura Pighi, Simone De Nitto, Gianluca Gianfilippi and Giuseppe Lippi The pronounced decline of anti-SARS-CoV-2 spike trimeric IgG and RBD IgG in baseline seronegative individuals six months after BNT162b2 vaccination is consistent with the need for vaccine boosters - e29

Joris R. Delanghe, Marijn M. Speeckaert

and Marc L. De Buyzere

ACE polymorphism is a determinant for COVID-19 mortality in the post-vaccination era - e32

Christoph Buchta, Jeremy V. Camp, Jovana Jovanovic, Ulla Radler, Elisabeth Puchhammer-Stöckl, Bernhard Benka, Wolfgang Huf, Mathias M. Müller, Andrea Griesmacher, Stephan W. Aberle and Irene Görzer A look at the precision, sensitivity and specificity of SARSCoV-2 RT-PCR assays through a dedicated external quality assessment round $-\mathrm{e} 34$ 
Luis García de Guadiana-Romualdo, Verónica Ramos-Arenas, María Dolores Rodríguez Mulero, Marta Hernández Olivo, Valerio Campos-Rodríguez, María Galindo Martínez, María Salomé Ros Braquehais, Luciano Consuegra-Sánchez, Mercedes González Morales and María Dolores Albaladejo-Otón

Value of hypocalcemia and thromboinflammatory biomarkers for prediction of COVID-19 severity during the second wave: were all the waves the same? - e38

Tong Zhu, Qing-Qing Cai, Jiao Yu and Xue-Song Liang Metagenomic next-generation sequencing (mNGS) confirmed a critical case of severe fever with thrombocytopenia syndrome virus (SFTSV) - e42

Anton Evenepoel, Johan Schiettecatte, Annelien Van Dalem and Ellen Anckaert

Biotin interference: evaluation of an updated thyroglobulin electrochemiluminescent immunoassay - e46

Hyunji Choi, Ziyoda Tashpulatova, Soo-Young Moon, Junghee Choi, Ji-Young Kim and Sun Min Lee Evaluation of the Beckman Coulter Access Procalcitonin Assay: analytical and clinical performance - e50
Francesca Sarlo, Cristina De Luca, Giacomo Moretti, Andrea Urbani and Silvia Baroni

Analytical performance evaluation of the new SST2 turbidimetric assay implemented in laboratory automation systems - e54

Louis Nevejan, Marnix Mylemans, Bert Vander Cruyssen, Muriel Stubbe, Stefanie Van Den Bremt, Laura Hofman, Maria Infantino, Mariangela Manfredi, Xavier Bossuyt and Lieve Van Hoovels

Pre-analytical recommendations and reference values for circulating calprotectin are sample type and assay dependent - e57

\section{Congress Abstracts}

Annual Meeting of the Royal Belgian Society of Laboratory Medicine: "Women's health: from puberty to menopause" Brussels, Belgium, November 1, 2021 - eA1 